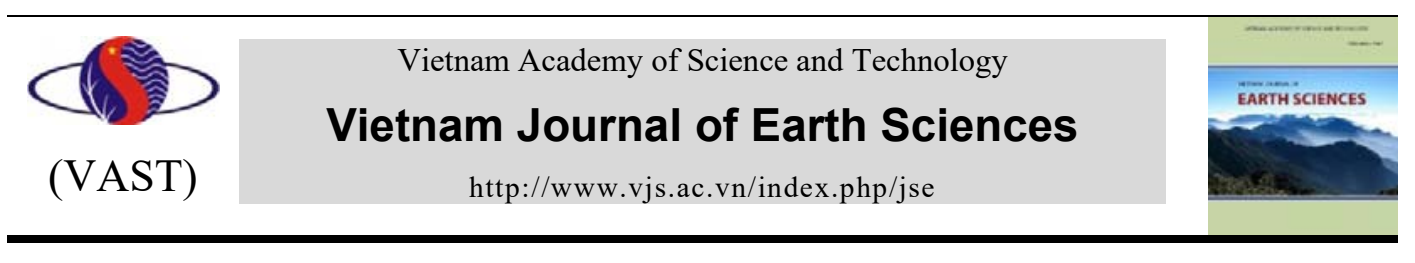

\title{
Mapping land cover using multi-temporal sentinel-1A data: A case study in Hanoi
}

\author{
Le Minh Hang*1, Vu Van Truong1, Nguyen Dinh Duong2, Tran Anh Tuan ${ }^{3}$ \\ ${ }^{1}$ Military Technical Academy, 236 Hoang Quoc Viet street, Cau Giay, Hanoi, Vietnam \\ ${ }^{2}$ Institute of Geography (VAST), Hanoi, Vietnam \\ ${ }^{3}$ Institute of Ecology and Biological Resources (VAST), Hanoi, Vietnam
}

Received 22 November 2016. Accepted 01 September 2017

\begin{abstract}
Land cover mapping is one of the most important applications of both optical and microwave remote sensing. The optical remote sensing recognizes land cover objects using spectral reflectance of the material constituting the land cover. The microwave remote sensing recognizes ground objects using backscatter, of which the intensity depends on the roughness of the ground's surface. Therefore, the multi temporal SAR images owning a lot of phenology information of land cover are the potential ideal data source for land cover mapping, in particular in the urban area. In this article, the authors present a new approach to the classification of land cover by using multi-temporal Sentinel-1A data. The experience data are single-pole (VV) in Interferometric Wide Swath mode (IW) collected from December 2014 to October 2015 along descending orbit over Hanoi, Vietnam. Decision tree method is applied base on analyzing threshold of standard deviation, mean backscatter value of land cover patterns, and combining double-crop rice classification image. The double-crop rice image is classified by rice phenology using multi-temporal Sentinel-1A images. The threshold in decision tree method is analyzed by field surveying data. The resulting classified image has been assessed using the test points in high-resolution images of Google Earth and field data. The accuracy of proposed method achieved $84.7 \%$.
\end{abstract}

Keywords: Multi-temporal SAR images; Land cover; Sentinel-1A; Decision tree classification.

(C)2017 Vietnam Academy of Science and Technology

\section{Introduction}

According to FAO (Food and Agriculture Organization of the United Nations), land cover is the observed as biophysical cover on the Earth's surface. Land cover, conventionally, is mapped by using satellite imagery, aerial photo, field survey, or the combination of these data.

"Corresponding author, Email: leminhhang81@gmail.com
Optical satellite imagery plays an important part in mapping land cover. Recognition of the land cover is based on spectral reflectance characteristics of land cover categories (Abdalla and Abdulaziz, 2012; Nguyen Dinh Duong et al., 2014; Li et al., 2004) or NDVI time series (Lambin et al., 1999; Myneni et al., 1995). However, optical imagery has many disadvantages due to weather condition and cloudiness. This is apparent 
truth for countries in the tropical region including Vietnam. The highest expectancy of cloud-free observation could be just one or two times per year only. It is difficult to extract land cover objects, particularly cultivated land if we use only one or two observations. Therefore, agricultural cultivation with harvest interval of three months cannot be detected sufficiently using such infrequent optical imagery.

In recent years, microwave remote sensing technology has been intensively used for monitoring natural resources. Many studies have indicated the correlation between radar backscatter and the different land cover types (Björn, 2009; Thiel et al., 2009) or agricultural land (Nguyen Ba Duy et al., 2015). For example, (Nguyen Ba Duy et al., 2015) extracted rice region of the Mekong Delta by using decision tree method with accuracy $92 \% \ldots$ The broad use of the former SAR systems was, however, quite limited due to high cost and low temporal resolution. The new SAR system as Sentinel-1A provides polarimetric data in high spatial and temporal resolution for allowing land cover mapping with a quite high accuracy up to $93.28 \%$ (Abdikan, 2016; Heiko, 2015; Wagner et al., 2012).

The Sentinel-1A, a European radar imaging satellite, was launched in 2014. The satellite was developed for the specific needs of the Copernicus program in collaboration with European Commission (EC) and European Space Agency (ESA). Sentinel-1A satellite provides SAR images in band C. The system operates in four observation modes offering medium and high spatial resolution data (up to $5 \mathrm{~m}$ ) in a swath up to $400 \mathrm{~km}$. Sentinel-1A data has two polarizations such as $\mathrm{VV}$ and $\mathrm{VH}$ and repeated observation cycle of 12 days. The data is public free.
In this paper, the authors used multitemporal Sentinel 1A data to map land cover in Hanoi city. Using means and standard deviations computed from the one-year multitemporal Sentinel 1A data helps us to find out phenology patterns for major land cover categories in the study area. By combining the phenology patterns and thresholds of mean backscatter values of major land cover types and applying decision-tree method, we succeed to develop automatically land cover map with detail cropland and developed land distribution.

\section{Study area and data used}

The study area is located in Hanoi city in the North Vietnam. Hanoi is situated between $20^{\circ} 53^{\prime}$ to $21^{\circ} 23^{\prime}$ North latitude and $105^{\circ} 44^{\prime}$ to $106^{\circ} 02^{\prime}$ East longitude (Figure 1). The Red River, a major river, flows through Hanoi. The main topography of Hanoi includes delta and hills. Hanoi has the humid and tropical climate.

Hanoi was chosen as the study area because it has enough dynamics to achieve the goals of this research. Moreover, Hanoi is a challenging area regarding land cover changes (urban sprawl). The cultivated land is being changed to developed land. Some parts of the cultivated land are not used and changed to barren land. In addition, the land cover of Hanoi is complex, it has many types such as developed land, barren land, cultivated land, forest land, water, and wetland...

In this study, the Sentinel-1A data in observation mode Interferometric Wide Swath (IW) with single VV polarization, acquired in a period from December 2014 to October 2015 has been used. Detail characteristics of the used data are shown in Table 1. 


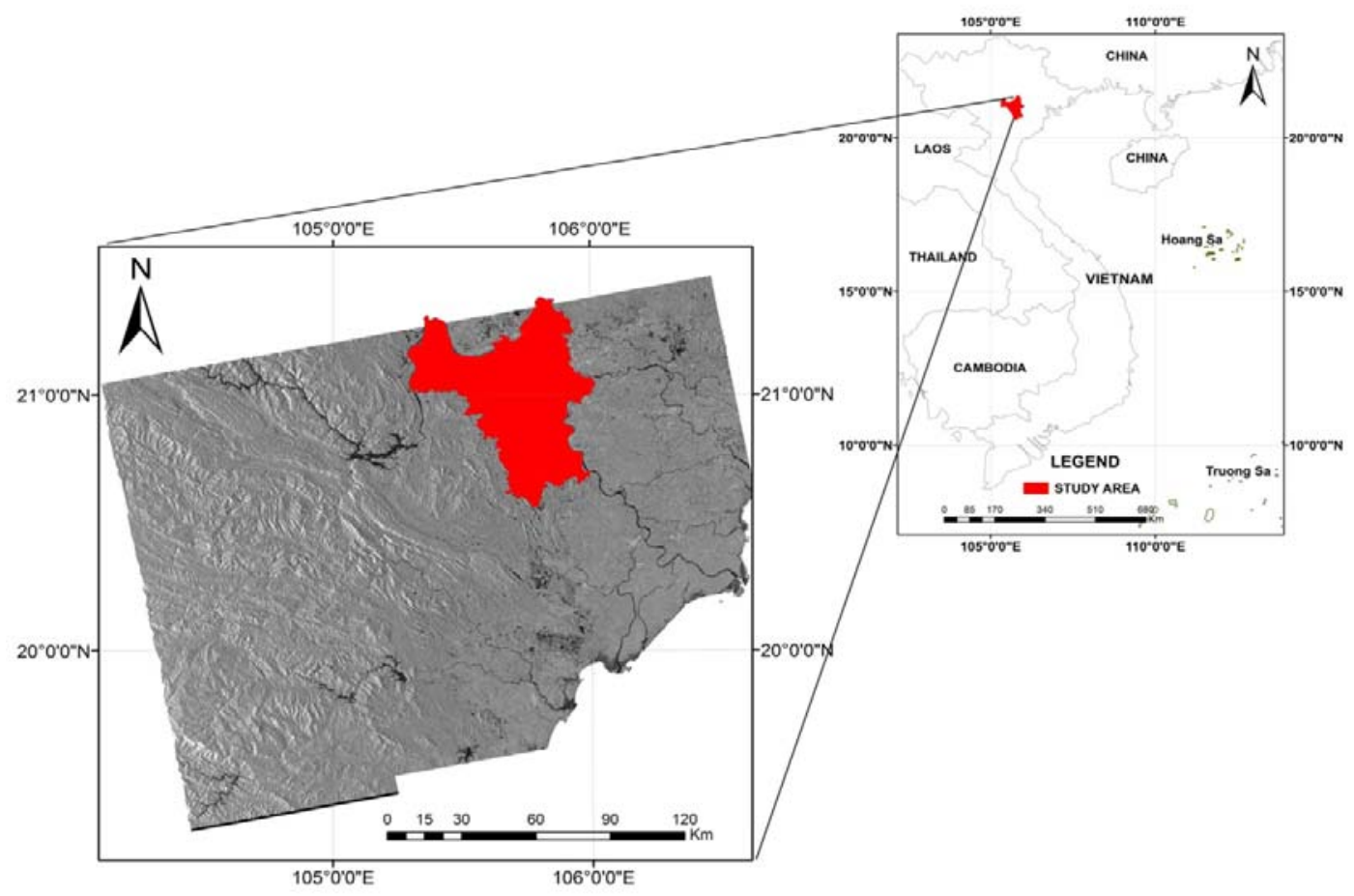

Figure 1. Location of study area

Table 1. Multi-temporal Sentinel-1A experiment data

\begin{tabular}{lc}
\hline \multicolumn{1}{c}{ Specifications } & Sentinel-1A experiment data \\
\hline Acquisition time & $13 / 12 / 2014 ; 06 / 01 / 2015 ; 23 / 02 / 2015 ; 19 / 03 / 2015 ; 12 / 04 / 2015$ \\
Acquisition orbit & $30 / 05 / 2015 ; 23 / 06 / 2015 ; 17 / 07 / 2015 ; 03 / 09 / 2015 ; 21 / 10 / 2015$ \\
Imaging Mode & Ascending \\
Imaging frequency & IW (Interferometry Wide Mode) \\
Polarization & C-band $(5.46 \mathrm{~Hz})$ \\
Data product & single VV polarization \\
Resolution mode & Level-1 GRD (Ground Range Detected) \\
Bit depth & $10 \times 10 \mathrm{~m}$ \\
& 16 bit \\
\hline
\end{tabular}

\section{Methods}

\subsection{Pre-processing}

The SAR data are preprocessed by the open source software SNAP Toolbox which is provided by the European Space Agency. Preprocessing of Sentinle-1A images consists of radiometric calibration, geocoding. The geocoding step involves a Range Doppler Terrain correction processing that uses the elevation data from the 3 arc-second DEM products from the Shuttle Radar Topography Mission (SRTM) provided by ESA. In this process, data are resampled and geocoded to a grid of $10 \mathrm{~m}$ spacing to preserve the $20 \mathrm{~m} \times 5 \mathrm{~m}$ spatial resolution according to the NYQuist sampling thermo (Nguyen Ba Duy et al, 2015). The pre-processing includes three main teps such as (1) Backscatter normalization to sigma-naught $\left(\sigma^{\circ}\right)$ of intensity band; (2) Resampled and geo-coded by DEM product and (3) Convert linear to/from dB (Figure 2). 


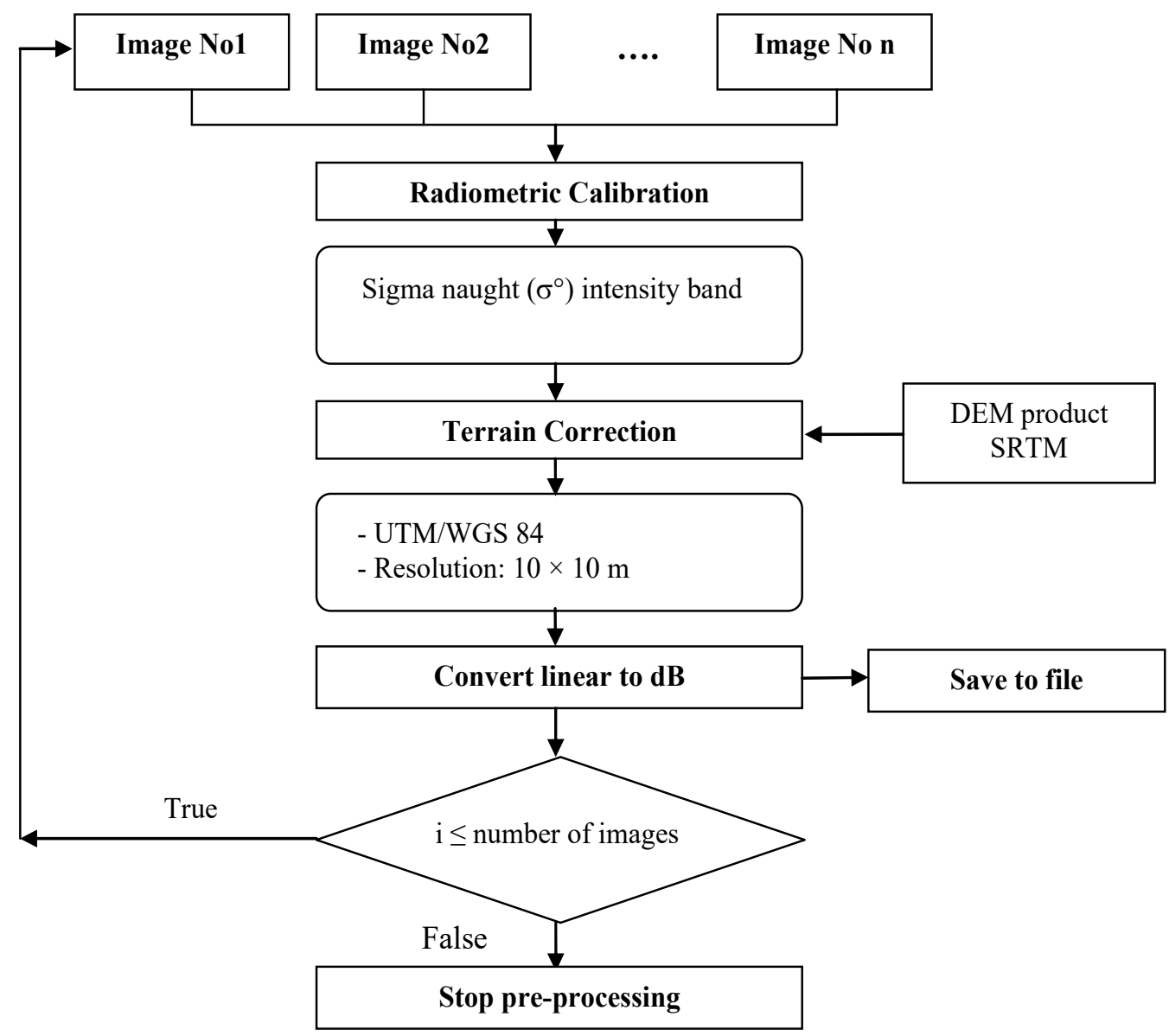

Figure 2. Pre-processing flowchart of multi temporal Sentinel-1A data

According to the theory of SAR image processing, the backscatter signal is not only influenced by the characteristics of land cover but also incidence angle. In order to extract the changed of land cover objects by backscatter values, it is necessary to adjust the effect of incidence angle by normalizing all acquisition to a common incidence angle by which intensity value is converted to sigma naught $\left(\sigma^{\circ}\right)$. This is described in Daniel Sabel's paper (Daniel et al, 2012). In this SNAP toolbox, the objective of SAR calibration output scaling applied by the processor must be undone and the desired scaling must be ap- plied. Level-1 products provide four calibrations Look Up Tables (LUTs) to produce $\sigma^{\circ}$. The LUTs apply a range-dependent gain including the absolute calibration constant. For GRD products, a constant offset is also applied. The radiometric calibration is applied by the following Eq (1):

$$
\sigma_{i}^{0}=\frac{\left|D N_{i}\right|^{2}}{A_{i}^{2}}
$$

where: $\mathrm{DN}_{\mathrm{i}}$-depending on the selected LUT, $A_{i}$ - beta-naught value (i). Bi-linear interpolation is used for any pixels that fall between points in the LUTs. 
Vietnam Journal of Earth Sciences, 39(3), 345-359

After normalized radar cross section, the data needs to be converted to $\mathrm{dB}$ by SNAP Toolbox. Figure $3 \mathrm{~b}$ shows the backscatter value in the cross section of the preprocessed image which was acquired on 13/12/2014. In Figure $3 b$ the backscatter of the near and far range is balanced. It is proved that the backscatter value of the preprocessed image is unaffected by the incident angle.

Another while, the stability backscatter of pre-processed multi-temporal images is evaluated by maximum, minimum, average and standard deviation values of overall the study area (Table 2).

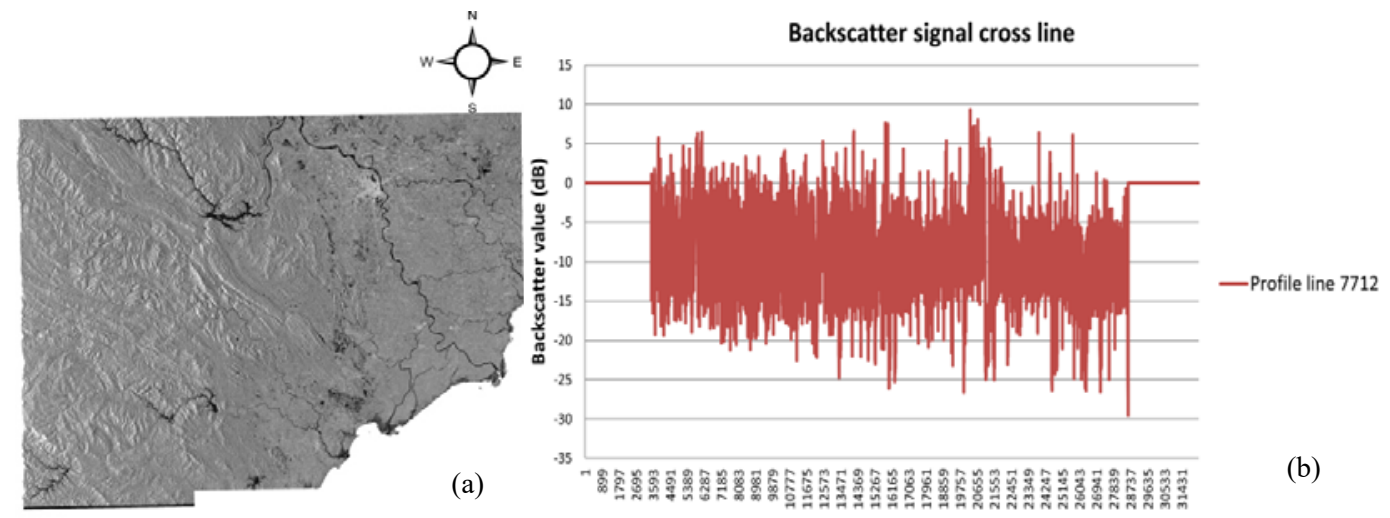

Figure 3. (a) Rotated Sentinel-1A image acquired on 13/12/2014 to azimuth; (b) Backscatter value in cross section at line 7712 of the pre-processed image

Table 2. Stability of backscatter value of pre-processed Sentinel-1A images

\begin{tabular}{|c|c|c|c|c|}
\hline Acquisition date & Minimum value & Maximum value & Average Value & Standard deviation \\
\hline $13 / 12 / 2014$ & -31.650 & 34.861 & -4.491 & 5.586 \\
\hline $06 / 01 / 2015$ & -29.671 & 35.580 & -4.787 & 5.958 \\
\hline $23 / 02 / 2015$ & -31.517 & 34.747 & -4.789 & 5.964 \\
\hline $19 / 03 / 2015$ & -29.661 & 36.022 & -3.941 & 4.988 \\
\hline $12 / 04 / 2015$ & -31.021 & 35.855 & -3.862 & 4.967 \\
\hline $30 / 05 / 2015$ & -30.287 & 35.424 & -3.873 & 5.015 \\
\hline $23 / 06 / 2015$ & -30.851 & 35.844 & -4.278 & 5.547 \\
\hline $17 / 07 / 2015$ & -30.371 & 36.358 & -3.897 & 4.998 \\
\hline 03/09/2015 & -30.839 & 35.353 & -3.763 & 4.976 \\
\hline $21 / 10 / 2015$ & -30.530 & 35.259 & -3.814 & 4.970 \\
\hline
\end{tabular}

\subsection{Fieldwork}

In this study, the authors sampled a total of 48 field sites by using the Locus map software on March 16, 2015 and December 22, 2014 (Figure 17b). Locus map software, an Android application, is capable of locating GPS loca- tions, collecting photos and recording tracks. The types of land cover objects in the study area consist of cultivated land, evergreen forest land, double-cropped rice land, barren land, fruit trees, developed land in urban and rural, water (rivers and lakes), wetland and trees in urban area (Figures 4-7). 
Le Minh Hang, et al./Vietnam Journal of Earth Sciences 39 (2017)

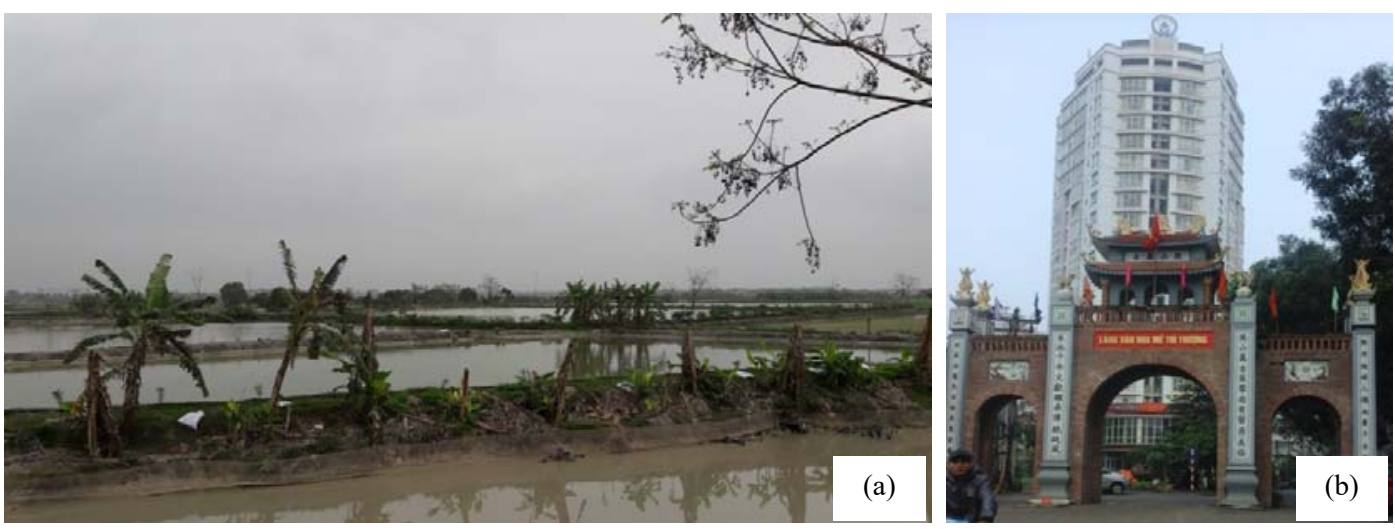

Figure 4. (a) Wetland in the Western Hanoi (16/03/2015); (b) High building (22/12/2014)

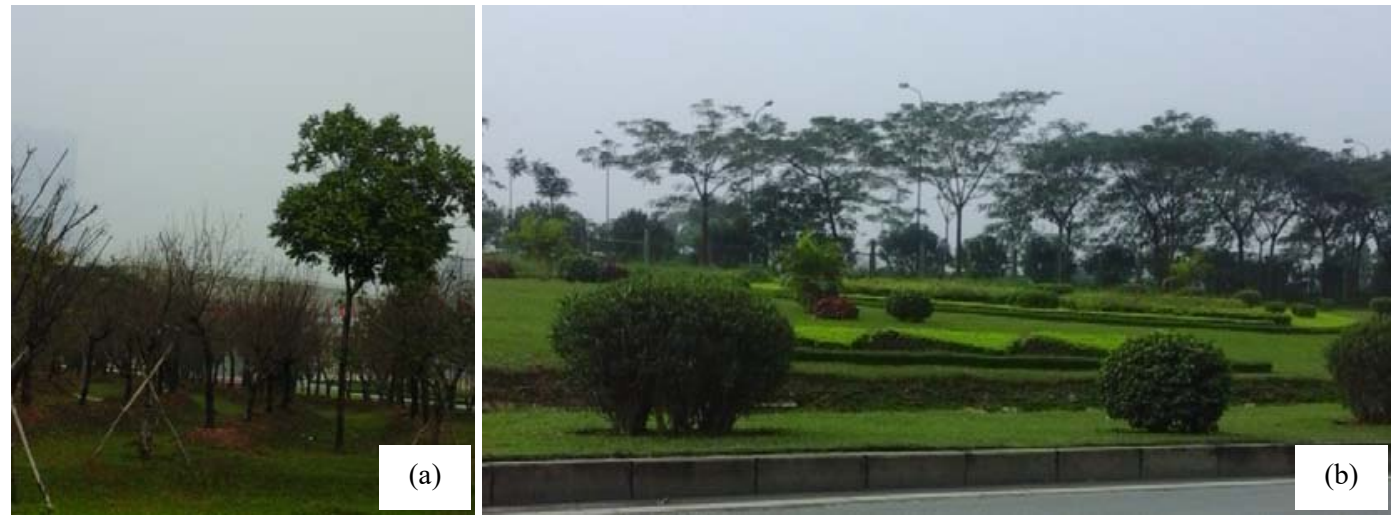

Figure 5. (a) Trees in urban area at Vietnam National Convention Center; (B) Trees on Thang Long Highway (22/12/2014)

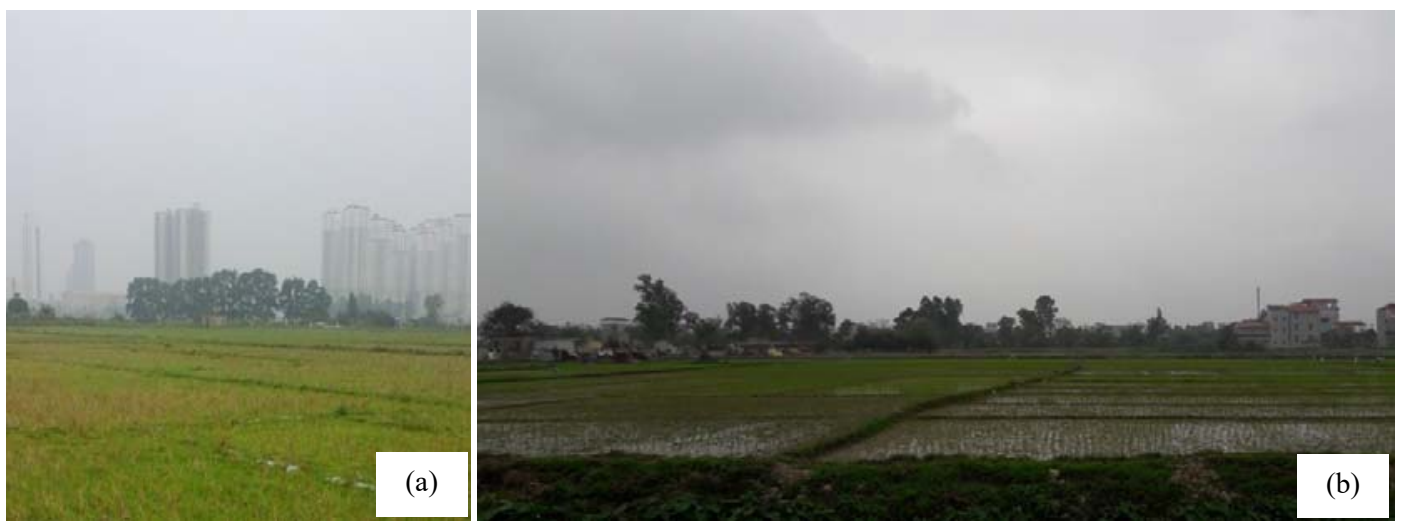

Figure 6. (a) Double-cropped rice fields in Dan Phuong, Ha Tay (22/12/2014);

(B) Double-cropped rice fields in Dan Phuong, Ha Tay (16/03/2015) 
Vietnam Journal of Earth Sciences, 39(3), 345-359

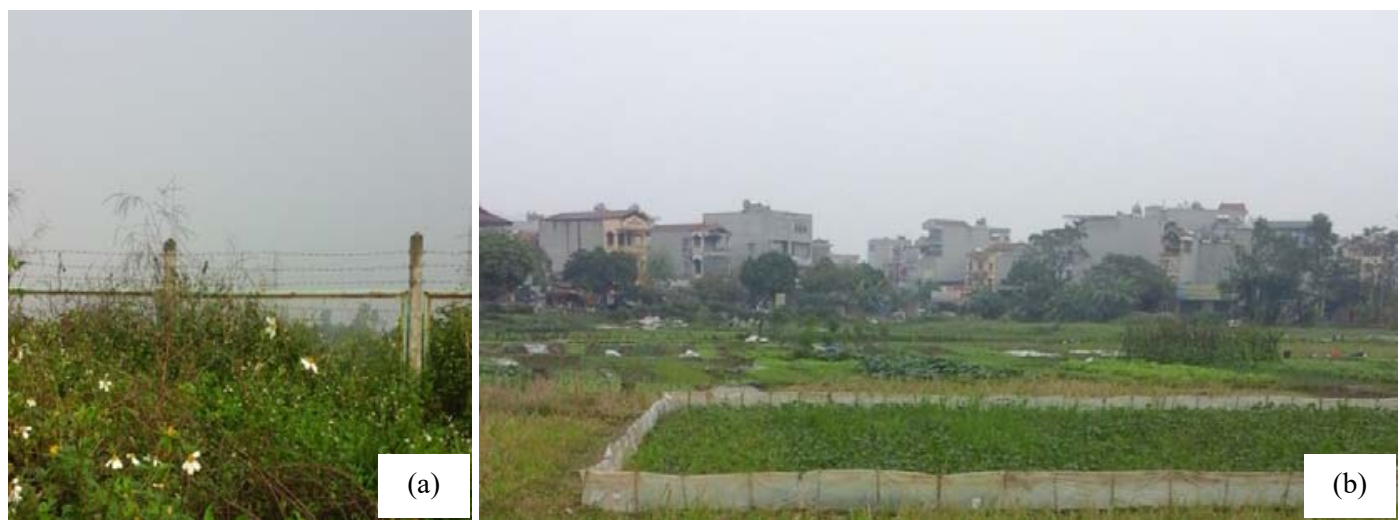

Figure 7. (a) Barren land in the city; (b) Difference type of crop is grown in paddy field (22/12/2014)

\subsection{Determining the phenology patterns}

\subsubsection{Analysis of SAR backscatter for land- cover types}

\section{Changed/unchanged patterns:}

Analyzing multi-temporal SAR images (from December 2014 to October 2015), land cover patterns can be divided into two main groups: (i) Changed land-cover patterns (patterns have changed during the timeframe of the study) and (ii) Unchanged land-cover patterns (patterns have not changed or changed little during the timeframe of the study).

The major changed patterns include cultivated land (for example double-cropped rice, other croplands) and wetland in the Western Hanoi because of changing the purpose of land use. The unchanged patterns are developed land, forest land, water and barren land. In which, forest pattern, in this study, is defined as trees in urban, evergreen forest and fruit-trees. As along river or lake, backscatter coefficient is sometimes higher than mean value because of moving of ships, boats,...

Figure 8 displays the RGB composite image of Sentinel-1A in three observation times. The different color in the composite image represents for different types of land cover. The white or black colors in RGB image are unchanged patterns because of stability of backscatter value in time-series image (Figure
$8 a)$. On the other hand, the color shades in RGB image are changed patterns because of having difference backscatter signal of each pixel in time-series (Figure 8b). To separate changed and unchanged land cover categories, we use mean and standard deviation of temporal backscatter. Standard deviation value is determined by the Eq. (2):

$$
\text { std }_{i}=\left(\frac{1}{n-1} \sum_{i=1}^{n}\left(x_{i}-\bar{x}\right)^{2}\right)^{\frac{1}{2}}
$$

where: $s t d_{i}$ is standard deviation value of multi-temporal image; $x_{i}$ is backscatter value of one pixel in each time; $\bar{x}$ is mean backscatter value of the multi-temporal image.

Averaged backscatter value of land-cover patterns:

Figure 9 and Figure 10 show the variation of the backscatter value of each land cover object in the time frame of the study. In Figure 9 , backscatter value of developed land in urban has the highest values ranging from $+15 \mathrm{~dB}$ to $+20 \mathrm{~dB}$, developed land in rural has the lower value than in urban from $+5 \mathrm{~dB}$ to $+10 \mathrm{~dB}$. By contrast, backscatter of water has the lowest value, ranging from $-20 \mathrm{~dB}$ to $-5 \mathrm{~dB}$ and forest land has the value from $-10 \mathrm{~dB}$ to $5 \mathrm{~dB}$. Backscatter of barren land has the same value as forest land. 
Le Minh Hang, et al./Vietnam Journal of Earth Sciences 39 (2017)

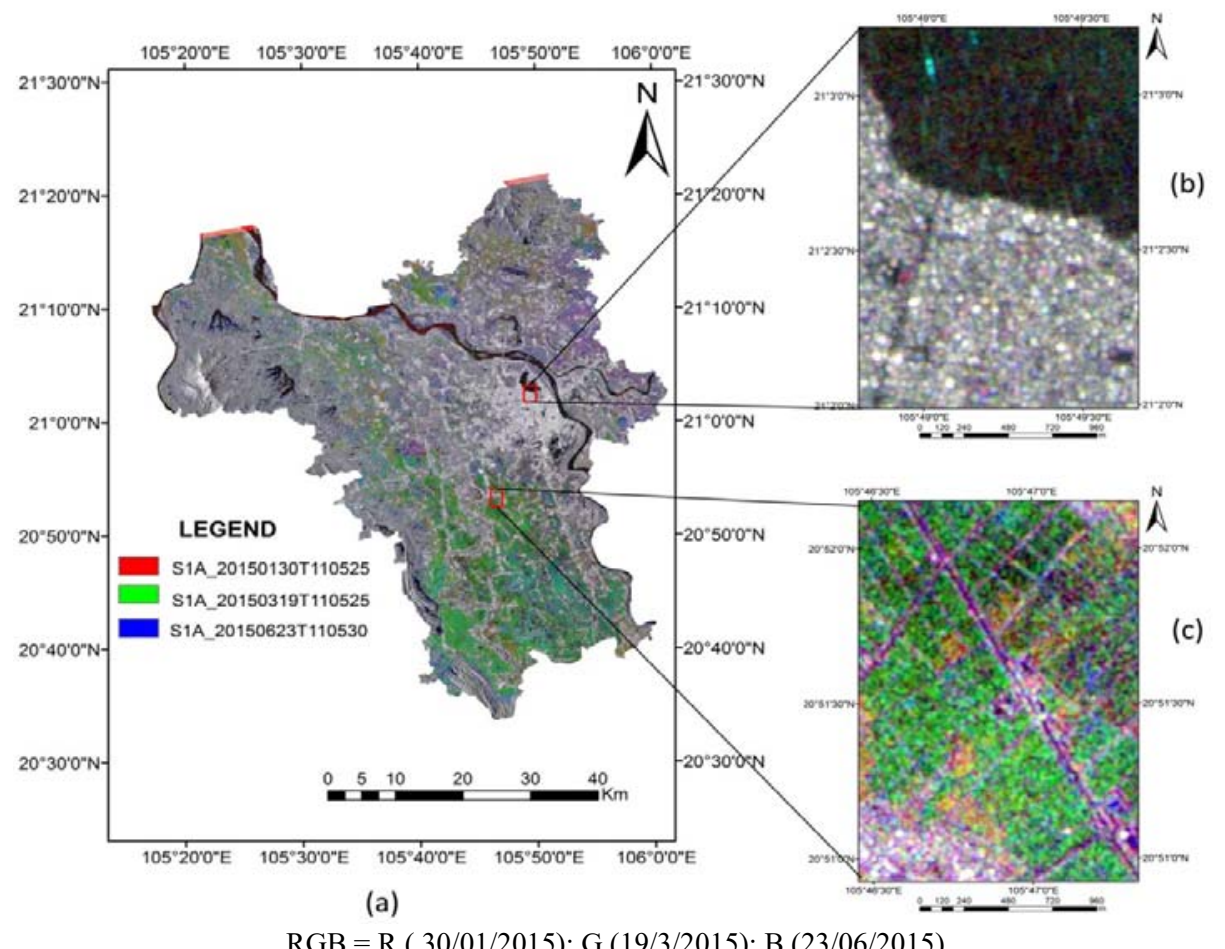

Figure 8. Color composite using temporal Sentinel-1 data (a) The unchanged patterns shown in black and white;

(b) The changed patterns shown in different color shades

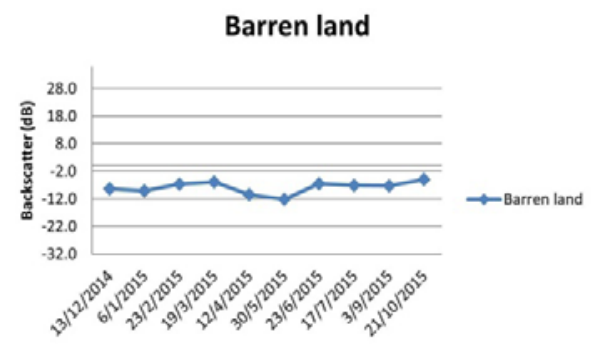

(a)

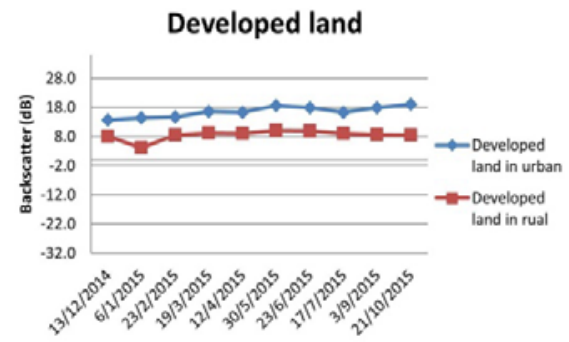

(c)
Water

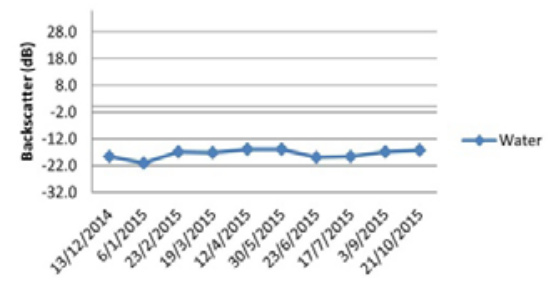

(b)

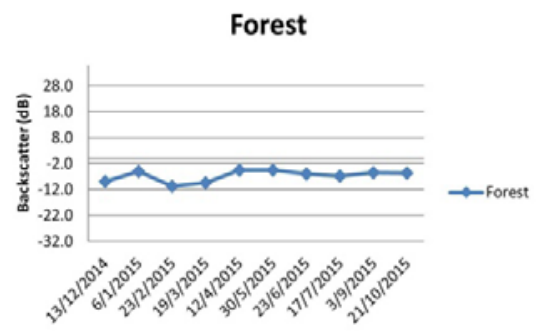

(d)

Figure 9. The backscatter value of barren land, water, developed land and forest on multi-temporal Sentinel-1A images 
Vietnam Journal of Earth Sciences, 39(3), 345-359

Double-cropped Rice

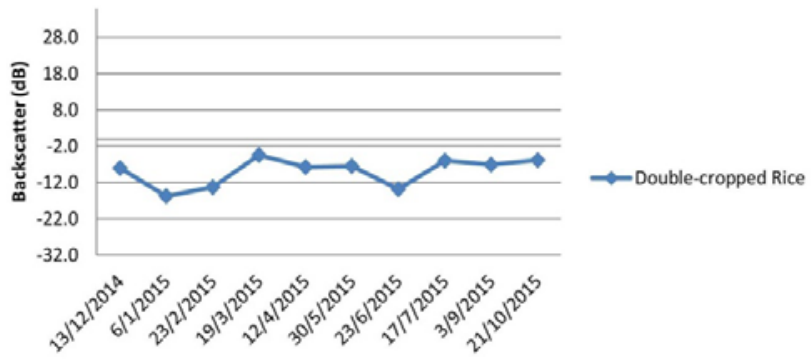

(a)

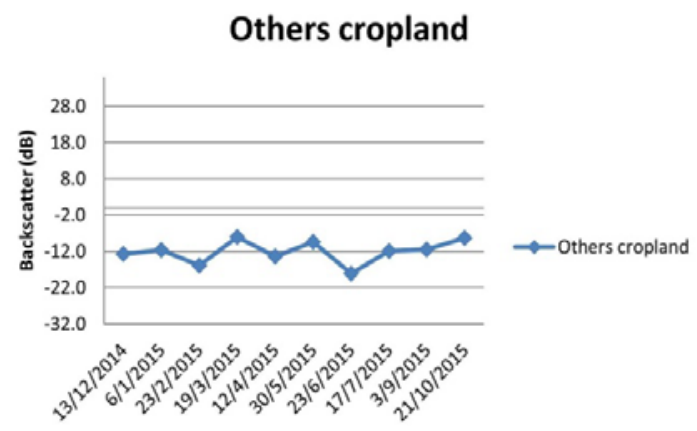

(b)

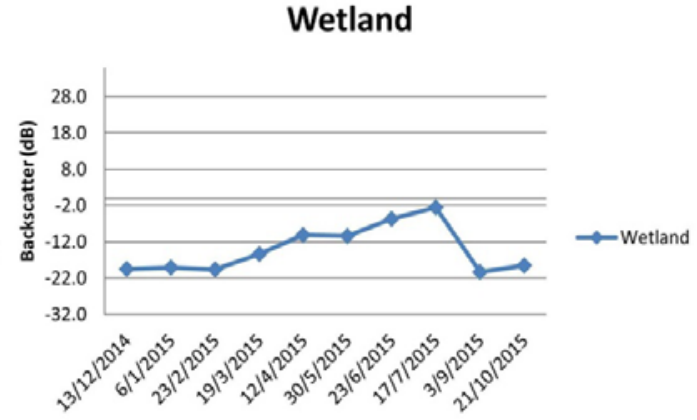

(c)

Figure 10. Backscatter value of double-cropped rice, other croplands and wetland on multi-temporal Sentinel-1A images

Figure11 shows that the standard deviation values of unchanged patterns (such as water, developed land in urban, developed land in rural, barren land, forest) are less than value $+2.85 \mathrm{~dB}$. By contrast, the standard deviation values of changed patterns (such as doublecropped rice, wetland, the other's cropland) are greater than $+2.85 \mathrm{~dB}$. Besides, with patterns having the same standard deviation values (such as water and developed land) we can use the mean backscatter value to discriminate them. For example, mean backscatter of water is $-7.586 \mathrm{~dB}$ whereas the value for developed land in urban is $+16.558 \mathrm{~dB}$. Therefore, we can extract water and developed land by using simultaneously both thresholds of standard deviation and mean backscatter value simultaneously. As a result, by combining the standard deviation and mean backscatter values of multi temporal SAR data, we can extract different land cover objects. However, Figure 10 and Figure 11 show that it is difficult to discriminate between rice and the others cropland by mean backscatter or standard deviation value because of having the same texture surface information.

Double-cropped rice phenology by multitemporal SAR images:

Many studies have proposed methods which help to extract rice regions by using multi-temporal SAR images (Nguyen Ba Duy et al., 2015; Yuan et al., 2009; Zhiyuan et al., 2011). Figure 12 shows the morphology of water rice crop with eight main stages. 
Le Minh Hang, et al./Vietnam Journal of Earth Sciences 39 (2017)

According to field survey data, there are two main crops in Hanoi. Summer-Autumn rice crop is from February to May and WinterSpring rice crop is from August to November.

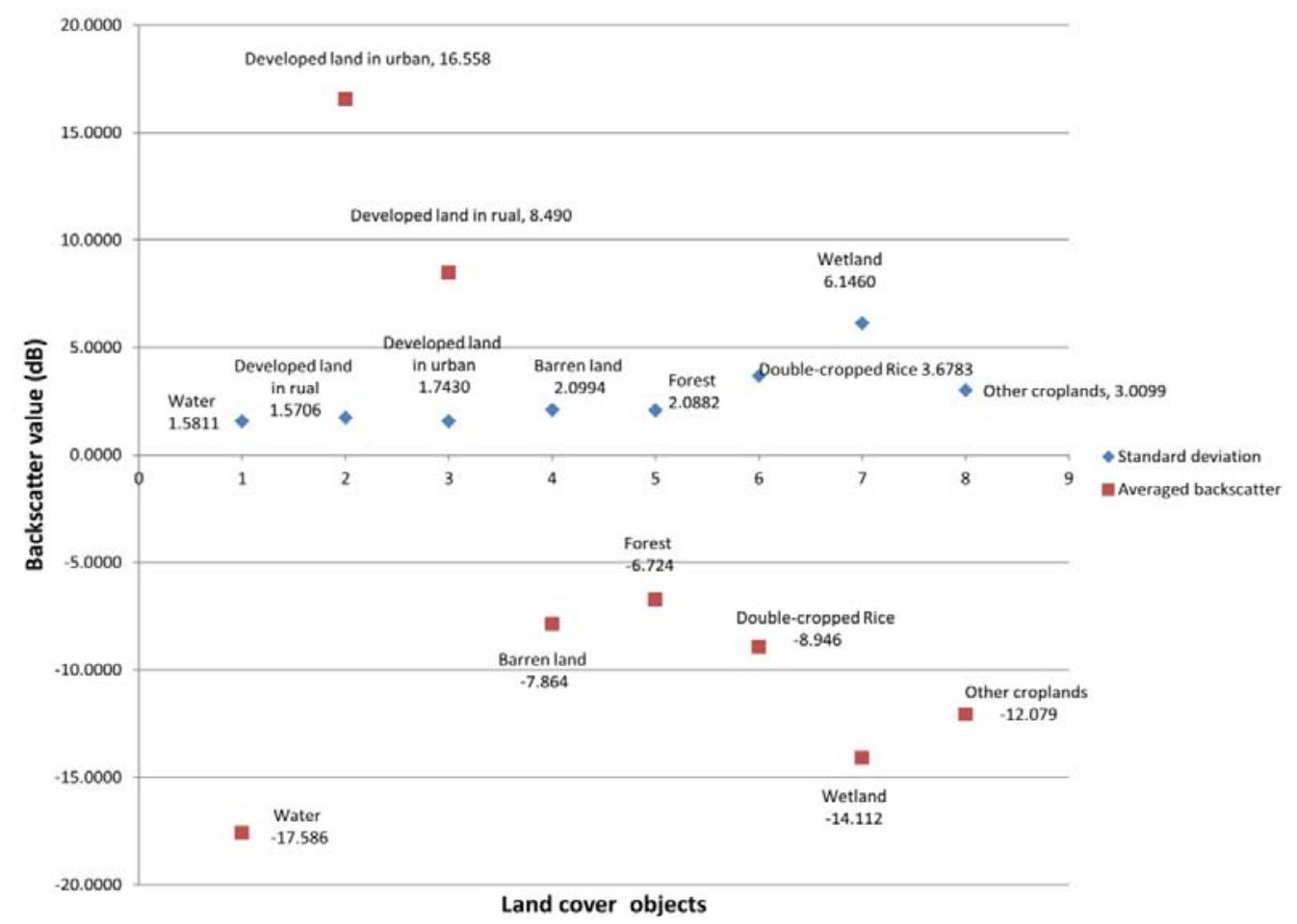

Figure 11. Standard deviations and mean values of backscatter of major land cover objects in Hanoi area

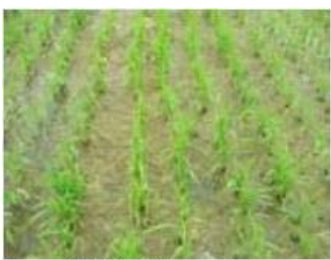

(a) Seedling stage

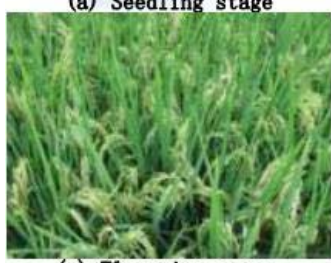

(e) Flowering stage

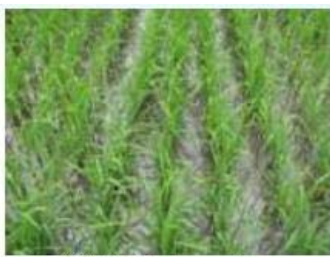

(b) Tillering stage

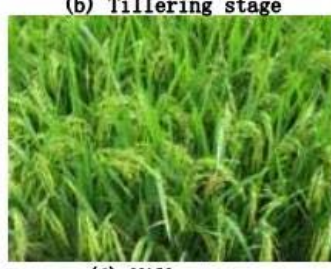

(f) Milk stage

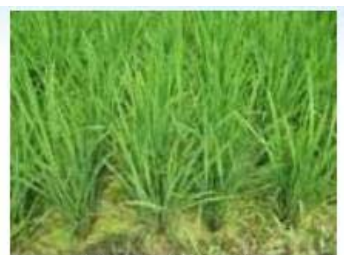

(c) Elongation stage

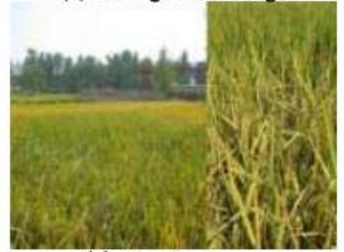

(g) Dough stage

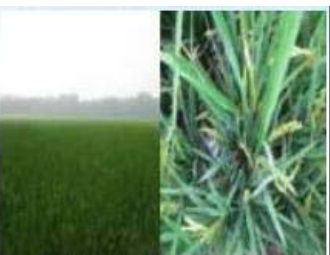

(d) Heading stage

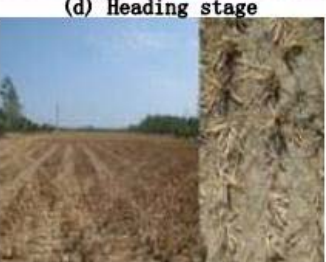

(h) Follow

Figure 12. Water rice morphology 
Figure 13 shows the correlation between phenology of double-cropped rice and backscatter values of multi-temporal Sentinel-1A data in Hanoi within 10 months. There are two periods with the lowest peaks backscatter values which correspond to follow stages. Based on the lowest peaks in January and June, we generate double-cropped rice classification image in binary format in which value 1 refers to rice and the value 0 stand for the other objects.

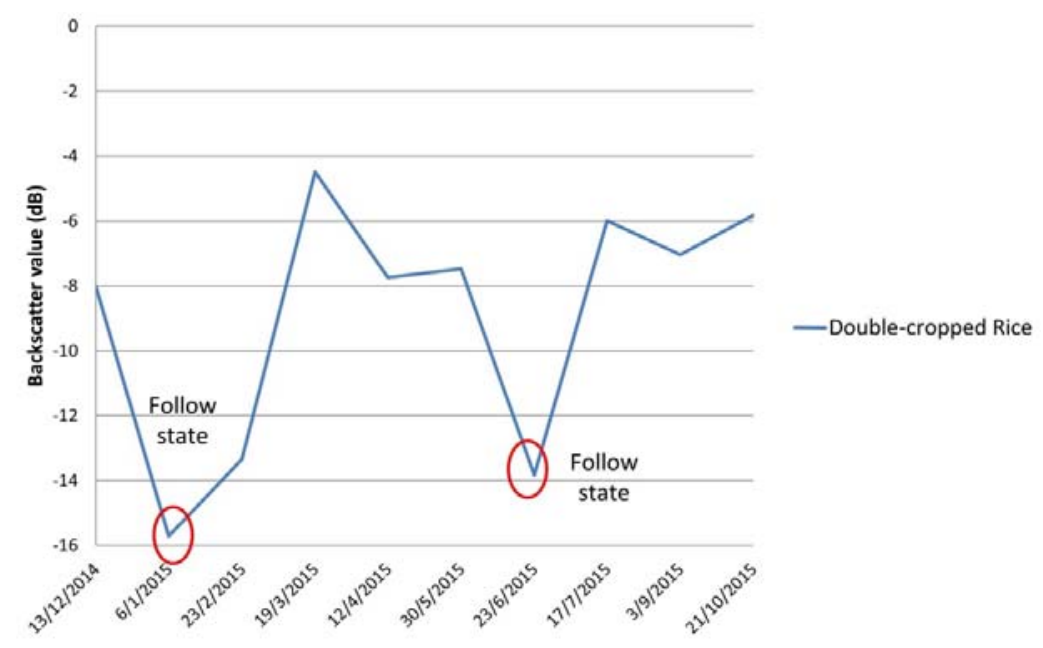

Figure 13. Phenology of double-crop rice with two low-peaks of backscatter

\subsubsection{Calculating the intermediate images}

As the result of section 3.2 and section 3.3, we calculate standard deviation image (Figure 14a) and mean backscatter image (Figure 14b) and double-cropped rice classification image (Figure 14c). The result images were calculated by MATLAB 2014a software.

Figure 14 shows the difference between land cover objects in the intermediate images. For example, the unchanged patterns such as water and developed land have low standard deviation values with the dark color, and the changed pattern's values cultivated land in the Western Hanoi has a high standard deviation with bright color. On the contrary, water has low-intensity value, developed land has highintensity value and cultivated land have the average value in the mean image. Figure $14 \mathrm{c}$ shows the double-cropped rice classification image which double-cropped rice are shown by black color and others pattern by white color. Figure 15 shows the difference intensity of standard deviation image, mean backscatter image and double-cropped rice image at the same area, in particular, rice land.

In this paper, the authors apply decision tree method to classify land cover. We propose using standard deviation image, mean backscatter image and double-cropped rice classification image, which are input data of decision tree method. The flowchart of the classification process is shown in Figure 16a and the thresholds in decision tree method are shown in Figure 16b. The threshold backscatter values of nodes in decision tree method are chosen based on field survey and analysis phenology patterns in multi-temporal Sentinel-1A images (Figure 11) and (Figure 14). 


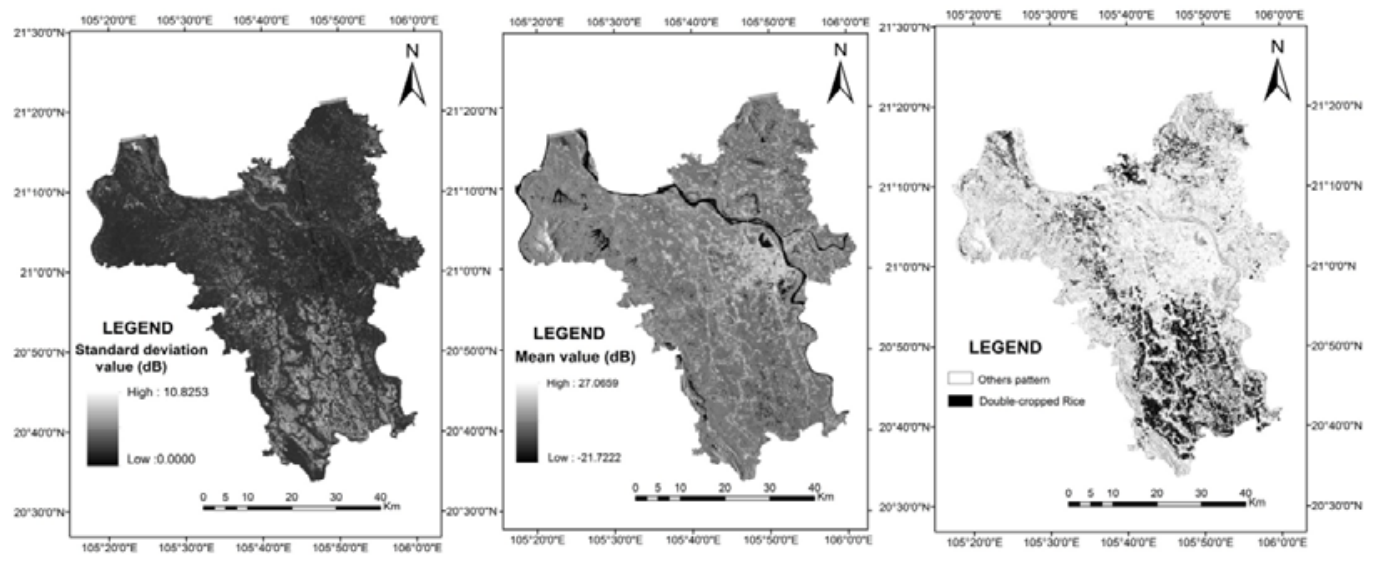

Figure 14. (a) Standard deviation image; (b) Mean backscatter image; (c) Double-cropped rice classification image
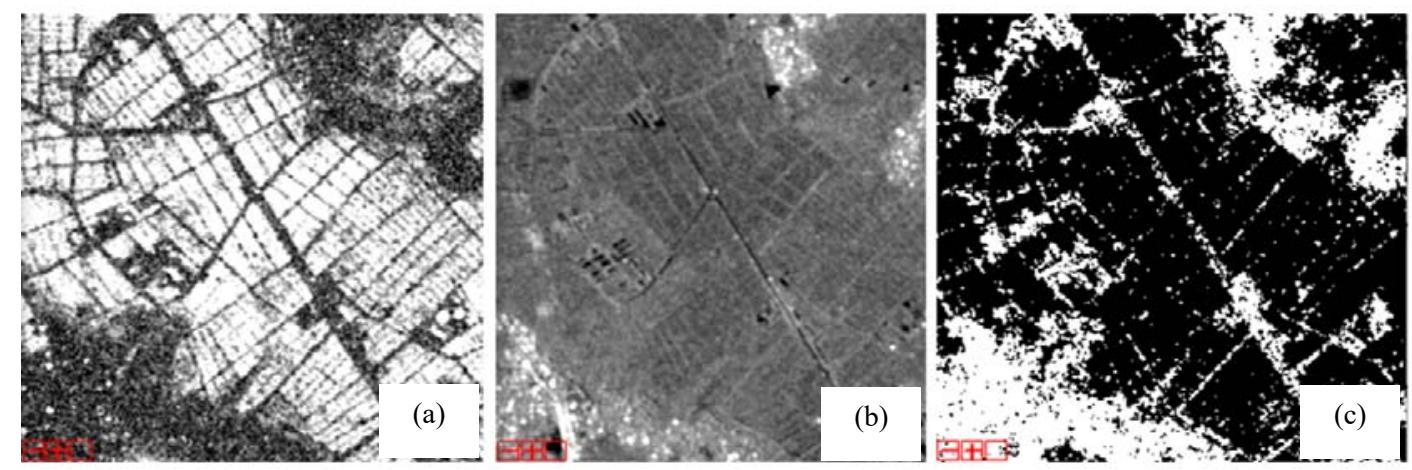

Figure 15. Different intensity of standard deviation images, mean backscatter image and double-cropped rice image at the same area; (a) Standard deviation image; (b) Mean image; (c) Double-cropped rice classification image

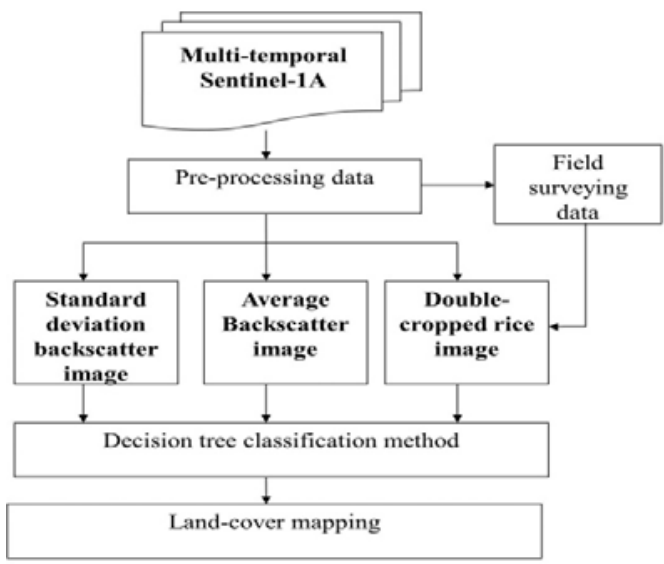

(a)

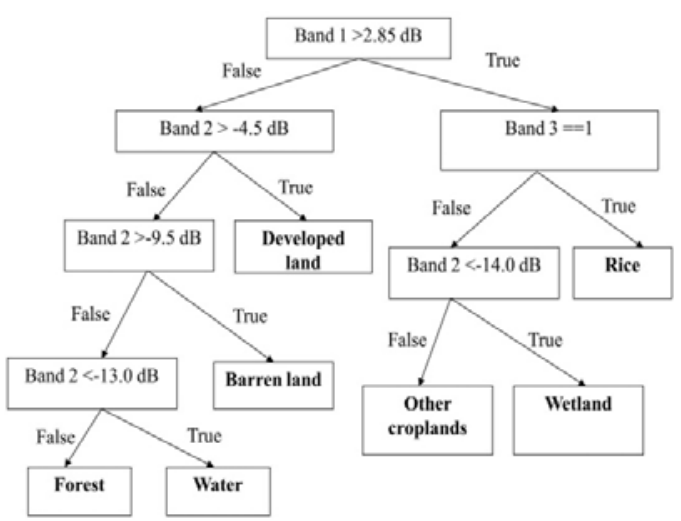

(b)

Figure 16. (a) The flowchart of proposed classification method; (b) The threshold of hierarchical class in decision tree method in which band 1 is the standard deviation image; band 2 is the mean backscatter image, and band 3 is the double-cropped rice classification image 


\section{Results and Discussion}

The result of mapping land cover by using multi-temporal Sentinel-1A images is shown in Figure 17. To assess the accuracy of the result, we use 48 field surveying points and 96 random test points in the study area (Figure 18). The test points are interpreted and checked on Google Earth's high resolution satellites images in 2014 and in 2015. The overall accuracy achieved $84.7 \%$.

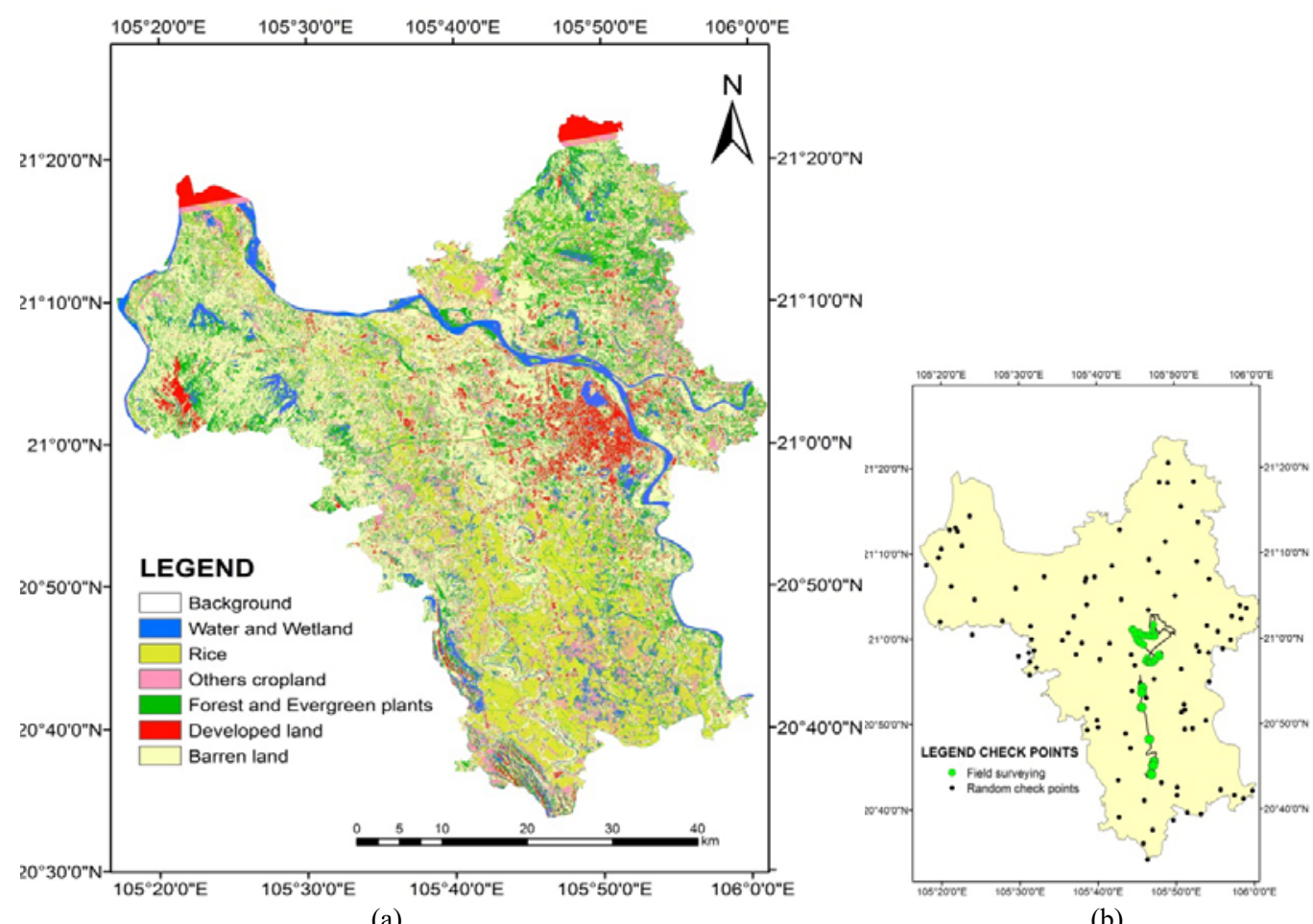

(a)

(b)

Figure 17. (a) Land cover mapping in Hanoi; (b) The location of field surveying points and random check points

According to the land cover mapping result by using multi-temporal Sentinel-1A images, the authors have the following discussions:

Firstly, interpretation and analyzing of land cover patterns in multi temporal SAR data should be combined optical satellite images and field surveying because SAR image only provides texture information surface of objects.

Secondly, the standard deviation value of multi-temporal Sentinel-1A images allows evaluating the changes of land cover objects in a period of time. As a result, using standard deviation and mean backscatter value as input data of decision tree method can classify land cover objects with high accuracy.
Land cover objects as developed land, rivers, lakes can be determined by multitemporal Sentinel-1A images with high accuracy (Figure 18c). The accuracy of classification developed land in this study is $78.8 \%$ in which there are 41 corrected points out of 52 test points. In particular, crop land is classified by analyzing the correlation between crop phenology and backscatter signal of multi temporal SAR images (Figure 18d). The accuracy of classification rice-land is achieved $82.6 \%$ including 19 correct out of 23 test points. Hence, the major crops such as rice, maize etc. in Hanoi can be exactly classified by multi-temporal Sentinel-1A images by using cropland phenology. 
However, the proposed method has some disadvantages. Firstly, land cover objects which have the same roughness surface, (e.g. the airport and lakes) are misclassified to the same class. Secondly, terrain shadow is misclassified to developed land because of terrain slope reflection phenomenon inside looking principle of SAR (Figure 18b).

In this study, the authors do not apply speckle noise filtering for the experience data because Sentinel-1A with Level-1 GRD data have been processed by the multi-look overlay. If we use adaptive filter method, the backscatter value in each time will be changed. As a result, it is difficult to find phenology patterns of land cover objects by time series SAR images. However, the final land cover classification results will be filtered by the majority to remove isolated pixels.

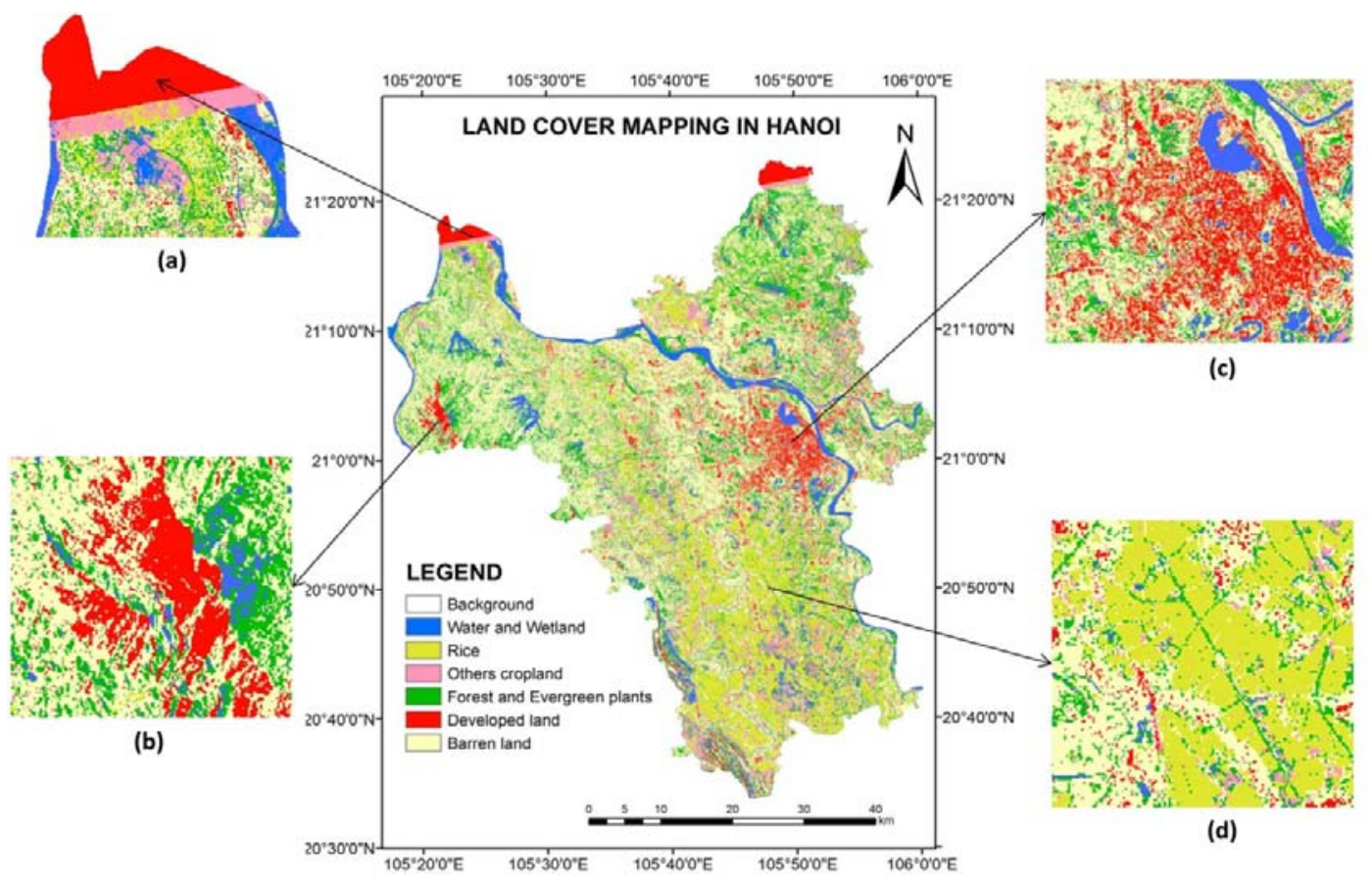

Figure 18. Analysis of classification result (a) Area of missing image; (b) Terrain shadows;

(c) Developed land in Hanoi; (d) Double-cropped rice land

\section{Conclusions}

The proposed method in this paper allows classifying land cover maps in delta area with complex land cover types. However, the limitations of SAR image, including terrain shadows, speckle noise, and similarity in the surface texture of land cover objects can cause confusions in classification result. By combining standard deviation, mean backscatter value and phenology of rice crop in decision tree method allows generating the land cover map in Hanoi using multi-temporal Sentinel-1A images. The overall estimated accuracy can achieve up to $84.7 \%$. The signal on SAR images provides the only backscatter generated by the roughness of ground surface object, and the observation is unaffected by weather condition. Meanwhile, the signal on optical images contains spectral reflectance information from land cover objects, which is more appropriate for recognition of land cover, but this information is hard to obtain due to weather condition. Therefore, in the future, 
Vietnam Journal of Earth Sciences, 39(3), 345-359

we need to study a combination of optical image and SAR image to improve the accuracy of land cover classification.

\section{Acknowledgements}

This research has been supported by a grant for the basic research project (No.105.08-2014.14) from National Foundation for Science and Technology Development (NAFOSTED) of Vietnam.

\section{References}

Abdalla M. Faid, Abdulaziz M., 2012. Monitoring landuse change associated land developement using multitemporal Landsat data and geoinformatics in Kom Ombo area, South Egypt. International Journal of Remote Sensing, 33, 7024-7046.

Abdikan S., et al., 2016. Land cover mapping using Sentinel-1 SAR data. XXIII ISPRS Congress, 12-19 July 2016, Prague, Czech Republic, 757-761.

Björn Waske, Matthias Braun, 2009. Classifier ensembles for land cover mapping using multitemporal SAR imagery. ISPRS Journal of Photogrammetry and Remote Sensing, 64, 450-457.

Daniel Sabel, Zoltan Bartalis, Wolfgang Wagner, Marcela Doubkova, Jean-Pierre Klein., 2012. Development of a Global Backscatter Model in support to the Sentinel-1 mission design. Remote Sensing of Environment, 120, 102-112.

Heiko Balzter, et al., 2015. Mapping CORINE Land Cover from Sentinel-1A SAR and SRTM Digital Elevation Model data using Random Forest. Remote Sensing, 14876-14898.

James R., Anderson E.E., 1976. A land use and land cover classification system for use with remote sensor data. Washington. Geological Survey, 964.

Lambin E.F., Baulies X., Bockstael N., Fischer G., Krug T., Leemans R., Moran E.F., Rindfuss R.R., Sato Y., Skole D., Turner B.L. II, Vogel C., 1999. Land-Use and Land-Cover Change (LUCC) Implementation Strategy; IGBP Report No.48/IHDP Report No.10. Sweden. International Geosphere-Biosphere Programme (IGBP), Stockholm.

Li J., Lewis J., Rowland J., Tappan G., Tieszen L.L., 2004. Evaluation of land performance in Senegal using multi-temporal NDVI and rainfall series. J. Arid Environ, 59, 463-480.
Lupo F., Linderman M., Vanacker V. Bartholomé E., Lambin E.F., 2007. Categorization of land-cover change processes based on phenological indicators extracted from time series of vegetation index data. International Journal Remote sensing, 28, 2469-2483.

Myneni R.B., Hall F.G., Sellers P.J., Marshak A.L., 1995. The interpretation of spectral vegetation indexes. IEEE Trans. Geosci. Remote Sensing, 53, 481-486.

Nguyen Ba Duy, Kersten Clauss Senmao Cao, Vahid Naeimi, Claudia Kuenzer, Wolfgang Wagner, 2015. Mapping Rice Seasonality in the Mekong Delta with Multi-Year EnviSat ASAR WSM Data. Remote Sensing, 7, 15868-15893.

Nguyen Dinh Duong, Anh Le Van, Thu Ho Le, 2014. Interpretation of land cover using spectral modulation pattern an example with Landsat 8 OLI image. Vietnam Journal of Earth Sciences, 36, 480-488. Doi: 10.15625/0866-7187/36/4/6436.

Online E.S., 2016. ESA EO Missions. Retrieved 2000, from Sentinel-1:

https://earth.esa.int/web/guest/missions/esa-operationaleo-missions/sentinel-1

Online E.S., 2016. SENTINEL-1 SAR User Guide Introduction. Retrieved 2000, from Overview: https://earth.esa.int/web/sentinel/userguides/sentinel-1-sar

Thiel C., Cartus O., Eckardt R., Richter N., Thiel C., Schmullius C., 2009. Analysis of multitemporal land observation at C-band. In Proceedings of the 2009 IEEE International Geoscience, doi:10.1109/IGARSS.2009.5417764.

Wagner W., Sabel D., Doubkova M., Hornacek M., Schlaffer S., Bartsch A., 2012. Prospects of Sentinel-1 for land applications. In Geoscience and Remote Sensing Symposium (IGARSS), IEEE International. IEEE, 1741-1744.

Yuan Z, Cuizhen Wang, Jiaping Wu, Jiaguo Qi, William A. Salas, 2009. Mapping paddy rice with multitemporal ALOS/PALSAR imagery in southeast China. International Journal of Remote Sensing, 30(23), 6301-6315.

Zhiyuan Pei, Songling Zhang, Lin Guo, Heather McNairn, Jiali Shang, Xianfeng Jiao., 2011. Rice identification and change detection using TerraSAR$\mathrm{X}$ data. Canadian Journal of Remote Sensing, 37, 151-156. 